\title{
POR UM PAISAGISMO CRÍTICO: UMA LEITURA SOBRE A CONTRIBUIÇÃO DE MIRANDA MAGNOLI PARA A AMPLIAÇÃO DO CORPUS DISCIPLINAR DO PAISAGISMO
}

\section{TO A CRITICAL LANDSCAPE}

ARCHITECTURE: A READING ABOUT THE MIRANDA MAGNOLI'S CONTRIBUTION TO THE INCREASING OF THE LANDSCAPE ARCHITECTURE AREA

Eugenio Fernandes Queiroga

Professor titular da FAU-PUC-Campinas, professor do Programa de Pós-Graduação em Urbanismo da PUC-Campinas; professor doutor da Faculdade de Arquitetura e Urbanismo da Universidade de São Paulo (FAUUSP).

E-mail:queiroga@usp.br 


\title{
RESUMO
}

Discorre-se e interpreta-se sobre a contribuição da arquiteta Miranda Magnoli para a ampliação do corpus disciplinar do Paisagismo. Discutem-se conceitos desenvolvidos e suscitados pelo trabalho de Magnoli e apresenta-se, com o caso da Faculdade de Arquitetura e Urbanismo da PUC-Campinas, um exemplo do estabelecimento de relações entre campos disciplinares para o trato do espaço urbano, em disciplinas de graduação e de pós-graduação. Tem-se claro a importância da arquiteta para elevar a outro patamar o nível de interlocução entre as áreas de arquitetura, paisagismo e urbanismo.

Palavras-chave: Paisagismo crítico, paisagem, ambiente, espaço livre, espaço público.

\begin{abstract}
It is discoursed and it interpreted on the contribution of architect Miranda Magnoli to extend the corpus of the Landscape Architecture discipline. Concepts developed for the work of Magnoli are argued and it is presented an example of the establishment of relations between knowledge areas for the treatment of the urban space, in disciplines of graduation and post-graduation, with the case of the Faculdade de Arquitetura e Urbanismo of the PUC-Campinas. The importance of the architect is had clearly to raise in another platform the interlocution level between the areas of Architecture, Landscape Architecture and Urbanism.
\end{abstract}

Key words: Critical landscape architecture, landscape, environment, open space, public space. 


\title{
POR UM PAISAGISMO CRÍTICO: UMA LEITURA SOBRE A CONTRIBUIÇÃO DE MIRANDA MAGNOLI PARA A AMPLIAÇÃO DO CORPUS DISCIPLINAR DO PAISAGISMO
}

\author{
TO A CRITICAL LANDSCAPE ARCHITECTURE: A READING \\ ABOUT THE MIRANDA MAGNOLI'S CONTRIBUTION \\ TO THE INCREASING OF THE LANDSCAPE \\ ARCHITECTURE AREA
}

\section{Introdução}

Artigo homenagem, oportunidade de refletir, retornar ao passado e retomar o futuro, aprendendo sempre sobre o pensar livre de ortodoxias de Miranda Maria Esmeralda Martinelli Magnoli. Assim, investindo-se de alguma ousadia, elabora-se uma leitura sobre pequena, mas significativa, parte da enorme contribuição de Magnoli para a área de Paisagismo. Primeiro apresentam-se questões conceituais desenvolvidas e suscitadas pelo trabalho de Miranda Magnoli, em seguida discorre-se rapidamente sobre a difusão do pensamento magnoliano no meio acadêmico e mostra-se, com o caso da Faculdade de Arquitetura e Urbanismo da PUC-Campinas, um exemplo do estabelecimento de relações entre campos disciplinares para o trato do espaço urbano, em disciplinas de graduação e de pós-graduação.

É bem provável que outros artigos neste número abordem alguns temas similares, devido à importância para a área de Paisagismo. Sempre cabe um outro olhar, aqui, bastante influenciado por Milton Santos, mestre que, certa vez, Miranda Magnoli permitiu que se conhecesse bem de perto, indicando sua orientação e, posteriormente, a de Maria Adélia de Souza. Quanta gratidão a esses três importantes intelectuais brasileiros.

Arrisca-se, nas linhas abaixo, discorrer e interpretar sobre a contribuição da arquiteta Miranda Magnoli para a ampliação do corpus disciplinar do Paisagismo. Sua obra, pelo que conhecemos, pouca apreciação internacional obteve até o presente. Isso de forma nenhuma limita seu pensar à paisagem e ao paisagismo brasileiro, ainda que seja inegável sua afirmação de brasilidade, seu interesse pelo país, seu povo e paisagens, tão distantes de sua terra natal, a ltália.

Afirma-se, neste ensaio, com contundência, que o trabalho de Miranda Magnoli, como arquiteta, como professora, como pesquisadora, contribui para ampliar o campo disciplinar do Paisagismo. Não apenas colabora para colocar a disciplina no país em pé de igualdade para uma interlocução internacional, mas, por sua dimensão crítica, permite avançar para além das visões pragmáticas sobre as relações entre paisagem e ambiente, notadamente norte-americanas, ou para além dos que buscam restringir o Paisagismo ao projeto de espaços livres. Não se trata, evidentemente, de afirmar uma pretensiosa vanguarda, pois as contribuições ao corpus discipli- 
nar do Paisagismo na contemporaneidade vem de vários centros do país e do planeta. $\bigcirc$ que se afirma é uma posição para o debate acadêmico e profissional, e uma posição consistente, como se pretende apresentar a seguir.

Agradece-se o privilégio do convívio mais que acadêmico com Magnoli, de forma alguma as imprecisões aqui lançadas têm outro responsável a não ser o autor deste artigo.

\section{Ampliando o Corpus Disciplinar do Paisagismo}

O objeto do Paisagismo não é o jardim. Esta afirmação, que para a área de Paisagismo já não é novidade, seguramente encontra resistências em parte expressiva dos colegas arquitetos que atuam na área do Projeto de Edificações e mesmo entre os que lidam com a cidade, no âmbito do planejamento urbano. Mas mesmo entre os arquitetos os quais atuam com Paisagismo, quantos não são os que acabam reduzindo sua práxis ao "projetar com as plantas"?

Com Magnoli, aprende-se que o objeto do Paisagismo é a paisagem e esta não se aparta do ambiente, o qual, por sua vez, é, assim como a paisagem, resultado dinâmico entre os processos sociais (econômicos, culturais e políticos) e os processos naturais (MAGNOLI, 1982).

A paisagem de Miranda Magnoli está longe de apresentar-se como uma definição pronta e acabada, mais importa a discussão conceitual - teoria e método - para o conhecimento, sempre processual, das paisagens, para a práxis propositiva, no âmbito do plano ou do projeto. A paisagem implica relações entre processos, relações sistêmicas e dialéticas, portanto, não se trata de uma abordagem restrita ao campo do entendimento sistêmico da geografia física ou da ecologia. Envolve uma dialética espacial. Nos princípios de método construídos por Miranda Magnoli para o conhecimento da paisagem, as escalas não podem ser apreendidas isoladamente, mas sim dialeticamente, trata-se, neste ponto, de posição muito similar ao esforço santosiano de compreensão do lugar diante da totalidade (SANTOS, 1996a e 2005).

A interlocução entre Miranda Magnoli e Milton Santos permitiu ao geógrafo uma maior compreensão das questões da arquitetura e, possivelmente, contribuiu em sua reflexão sobre a emotividade e o espaço, indo além das racionalidades mais habitualmente trabalhadas pela geografia crítica. Por sua vez, é provável que do diálogo entre ambos, arquiteta e geógrafo, lançou-se com muita clareza, entre o findar dos anos 1970 e início dos anos 1980, uma nova base de entendimento disciplinar na área do Paisagismo, o que se propõe aqui denominar de "Paisagismo Crítico"; do qual, sem dúvida, a tese de livre-docência de Miranda Magnoli (1982) constitui-se em marco fundante.

Magnoli, ao afirmar que a paisagem é resultado dinâmico entre processos sociais e processos naturais, adota uma perspectiva crítica, comum à geografia crítica, e já não aceita definir a paisagem simplesmente como a porção do território que a vista alcança a partir de um ponto privilegiado. Essa definição, encontrada em dicionários, mas também empregada pela geografia, pouco auxilia na compreensão dos processos que engendram a paisagem; descrever paisagens é já insuficiente para compreendê-las. Situação similar se observou para os geógrafos críticos, para os quais descrever o espaço já não bastava, era necessário compreender dialeticamente os processos que o constituíam.

A dimensão social do espaço para Milton Santos encontra paralelo na dimensão social da paisagem de Miranda Magnoli. À atenção para a dialética social que caracteriza as ciências sociais de epistemologia marxista coloca-se um passo além para ambos, o espaço (Santos) e a paisagem (Magnoli) não são apenas suporte ou cenário para o processo social. Não se trata de compreender o movimento dialético da sociedade no espaço ou na paisagem, mas de compreender a dialética do espaço (Santos), ou da paisagem (Magnoli), pois como afirmou Santos (1985), é preciso compreender o espaço enquanto instância social no mesmo nível em que são instâncias 
sociais a economia, a cultura e ideologia e a política, somente assim pode-se compreender o movimento (dialético) da sociedade. Dessa maneira, compreender a paisagem é reconhecer a dialética social que se processa entre todas as instâncias sociais, não apenas entre economia (estrutura) e cultura-ideologia e política (superestrutura).

Afirmar esse paralelo entre o espaço e a paisagem não significa dizer que são a mesma coisa. O espaço - humano - apresenta-se como totalidade maior, pode-se falar em espaço global, espaço-mundo, o mesmo não se aplica à paisagem. Há processos espaciais que se realizam em redes descontínuas, formadas por pontos - localizações - específicas do planeta, inclusive em diferentes territórios. A paisagem, por sua vez, é sempre contínua. A dimensão sistêmica do espaço é, portanto, mais ampla e complexa que a da paisagem, ou melhor, das paisagens. Reafirma-se o espaço como categoria fundante da geografia e pode-se adotar como categorias internas e analíticas do espaço: o lugar, a paisagem e o território. Toda paisagem é parte do espaço total, mas nem todo espaço está contido em uma paisagem. $\bigcirc$ espaço encerra uma totalidade social e geográfica, a paisagem é um recorte, uma particularidade.

É preciso enfatizar que a paisagem proposta por Miranda Magnoli vai além da paisagem proposta pela geografia, mesmo a geografia crítica. Para a geografia a paisagem se reduz à forma percebida, o espaço para Milton Santos (1988) possui valor ativo, é vivo, pois é constituído da indissociabilidade entre um sistema de objetos e um sistema de ações. A paisagem, para a geografia, estaria no domínio do sistema de objetos, das formas, das aparências. A paisagem é "trabalho morto" na expressão empregada por Milton Santos (1996b). A paisagem de Magnoli é viva, não se coloca como mero suporte do sistema de ações. Pode-se afirmar, em uma perspectiva paisagístico-crítica que as ações são, também, parte constituinte da paisagem, a dinâmica da paisagem não apenas se transforma ao modificar-se o sistema de objetos, mas ao realizar-se o sistema de ações, a cada momento, isto é, aliás, parte mesmo da visibilidade que caracteriza intrinsecamente a paisagem. Essa visibilidade, ou, de forma mais ampla, essa dimensão perceptível é um dos elementos que torna a paisagem distinta das demais categorias internas do espaço - o lugar e o território.

A paisagem de Miranda Magnoli constitui-se, portanto, em uma grande contribuição para a área de Paisagismo. Avança-se para a construção de um Paisagismo crítico, conforme se propõe entender e denominar neste ensaio. Permite-se uma interlocução com as disciplinas sociais que também se ocupam do espaço humano. A paisagem dialeticamente compreendida abre novos caminhos não apenas para as práticas ditas científicas, mas para a práxis do projeto e do planejamento da paisagem e do ambiente em bases muito mais adequadas que as verificadas por abordagens de fundamentação epistemológica marcada pelas ciências naturais, como, por exemplo, a ecologia da paisagem.

Uma perspectiva crítica para a disciplina de Paisagismo não significa abdicar da temática ambiental, pelo contrário, compreende-se o ambiente como produto material dinâmico, decorrente das inter-relações entre os processos sociais e as relações ecossistêmicas dos elementos do suporte biofísico. Tais interações compõem, sistemicamente, cada ambiente e a biosfera. $\bigcirc$ ecúmeno conjunto das regiões habitadas pelo homem - hoje corresponde a toda a superfície do planeta; não se pode apartar homem e natureza, trata-se, evidentemente, de uma "natureza segunda" de acordo com a acepção marxista. Igualmente não se deve isolar o homem da sociedade, o que levaria a uma abstração fictícia do homem. Dessa forma, não se aplica mais a expressão meio natural, trata-se, como afirmou Milton Santos (1996a), de um meio técnico-científicoinformacional, ou, mais ainda, de um meio técnico-científico-informacional e comunicacional (QUEIROGA, 2001), mais ou menos denso e evidente nessa ou naquela paisagem, neste ou naquele lugar ou fração do território.

O empenho de Miranda Magnoli em problematizar de forma relacionada e crítica a paisagem e o ambiente, tendo como objetos mais recorrentes os ambientes urbanos brasileiros, permitiu 
uma enorme ampliação do campo disciplinar do Paisagismo brasileiro. De um lado Magnoli se apoiava na experiência estadunidense do planejamento da paisagem e do ambiente, sem dúvida um dos locais onde mais cedo se constitui esse campo de estudos e práticas; por outro lado, reconhece a importância das contradições socioespaciais que não apenas impactam o ambiente, mas o constituem. Miranda Magnoli contribui desde o final dos anos 1970 para uma perspectiva crítica no trato das questões ambientais. Contrária a expressões reducionistas como "temática ambiental", como se o ambiente fosse apenas um "capítulo inicial" de todo plano diretor, propõe que a dimensão ambiental seja integrante dos estudos e propostas espaciais, quer no âmbito do projeto de espaço livre quer no do planejamento urbano e regional, isto já no início dos anos 1980, antes da promulgação da ampla, mas nem por isso eficiente, legislação ambiental brasileira.

Outra importante discussão conceitual desenvolvida por Magnoli refere-se à noção de espaço livre. A paisagista, pensando nas várias escalas espaciais, afirma ser o espaço livre aquele livre de edificação ou de urbanização. Tem-se, assim, uma possibilidade de atuação paisagística seja nos projetos e planos urbanos, seja no âmbito do planejamento regional. Trata-se, aparentemente, de uma conceituação simples, muito operativa. Os espaços livres assim compreendidos são não apenas os jardins, parques e praças, mas todos os espaços livres urbanos - avenidas, ruas e seus passeios, orlas de rios e mares, corpos d'água como lagos e reservatórios, entre outros, quintais e pátios descobertos - e os espaços externos aos tecidos urbanos - as matas, campos cultiváveis, etc. Evidentemente, alguns desses espaços são mais comumente tratados paisagisticamente, porém o que se coloca é a potencialidade de manejar-se a paisagem, seus espaços livres, de forma mais sistêmica, compreendendo os diferentes papéis que tais espaços podem oferecer: das áreas de convívio público, às áreas de proteção ambiental, dos jardins privados ao entendimento do sistema viário como parte integrante também do sistema de espaços livres de uma cidade ou região com várias potencialidades: cênicas, ambientais e apropriações públicas diversas.

Ao Paisagismo, assim compreendendo os espaços livres, compete muito mais do que o projeto das áreas de lazer, particulares e públicas, cabe analisar e propor, também, espaços de usos múltiplos, como as ruas e suas calçadas, os reservatórios de água, seu necessário controle ambiental, mas também seu aproveitamento para fins recreacionais; o papel político e ideológico simbólico e de representação pública - presente em tantas praças centrais brasileiras; da preservação de espaços livres e paisagens enquanto patrimônios históricos; dos graus de conservação e de apropriação humana do patrimônio ambiental das diferentes unidades de conservação do país; enfim, trata-se de um campo disciplinar bastante complexo, por mais simples que pareça ser a noção de seu principal objeto de trabalho: o espaço livre, livre de edificações ou livre de urbanização.

A ênfase na discussão do espaço livre público, seja nos cursos ou trabalhos publicados por Magnoli, é outra marca da perspectiva crítica com que a professora trata a disciplina de Paisagismo. É preciso resistir aos sabores do mercado profissional quando se constitui um campo do conhecimento acadêmico, mesmo quando tal campo apresente como finalidade principal a formação profissional para atuação prática. A ênfase no espaço livre público se constitui como uma proposta crítica à produção corrente dos espaços urbanos das grandes cidades, nas quais os empreendimentos privados que negligenciam a esfera pública são cada vez mais freqüentes e aceitos por várias camadas sociais e mesmo com a anuência do poder público. Trabalhar no ensino, pesquisa e extensão, com os espaços livres públicos não se constitui em uma perspectiva nostálgica, pelo contrário, busca-se garantir a qualificação das cidades para a vida pública, com todos os conflitos, potencialidades e dinâmicas que tal esfera de vida pode propiciar. Trata-se de uma opção política, em última instância de uma ética paisagística comprometida com a cidadania, com a criação de um ambiente humano o qual não negligencia as condições ecológicas nem 
a luta por uma sociedade mais justa. A paisagem de Miranda Magnoli se constitui, portanto, muito além dos jardins, mesmo quando ela está a projetar jardins privados, de residências ou shopping centers.

\section{Algumas Notas Sobre a Difusão do Pensamento Magnoliano: O Caso da PUC-Campinas}

Miranda Magnoli vem formando professores e pesquisadores desde os anos 1970, quando constituiu um grupo de docentes de Paisagismo na Faculdade de Arquitetura e Urbanismo da Universidade de São Paulo - FAUUSP. Graças a seu empenho, constituiu-se o Grupo de Disciplinas Paisagem e Ambiente - GDPA - junto do Departamento de Projeto da FAUUSP. Hoje tal grupo conta com 11 professores, certamente o maior do país na área de Paisagismo, e constitui-se na base da área de concentração Paisagem e Ambiente do Programa de Pós-Graduação em Arquitetura e Urbanismo da FAUUSP. As teses e dissertações produzidas na área, apenas na FAUUSP, já ultrapassavam 60, até 2003 (GALENDER, 2003), e são em número próximo os atuais orientandos de pós-graduação em Paisagem e Ambiente.

O número de ex-orientandos de Magnoli que atuam como docentes nas mais diversas escolas do país é bastante significativo, a eles se somam um número ainda maior de professores formados por ex-alunos de Miranda Magnoli, atuando majoritariamente na área de Paisagismo, mas também em Urbanismo e mesmo nas cadeiras de Projeto de Edificações. Tais trânsitos disciplinares demonstram a riqueza do pensamento magnoliano, constituindo uma disciplina crítica a qual se presta à interlocução com as demais disciplinas que tratam do espaço, notadamente do espaço urbano e regional.

Para a compreensão e proposição do espaço na escala das cidades, fica clara a interface entre as várias disciplinas que se ocupam do urbano, quer no âmbito da ciência (Geografia Urbana, Sociologia Urbana, Antropologia Urbana, Economia Urbana) quer das disciplinas propositivas (Paisagismo, Planejamento Urbano e Urbanismo). Mas se o urbano é objeto de várias disciplinas, reconhecer a paisagem como uma de suas importantes dimensões permite um diálogo mais rico entre os vários campos disciplinares; mais ainda, entre vários saberes, nem todos eruditos, como os advindos das práticas cotidianas de todos os grupos sociais que constituem o espaço e as paisagens urbanas; seja no âmbito dos métodos para sua compreensão, seja na perspectiva propositiva.

Como exemplo de um maior intercâmbio entre os campos disciplinares do Paisagismo e do Urbanismo discorre-se abaixo sobre experiência pessoal realizada desde 1990 na PUC-Campinas. Naquele ano, iniciou-se, na disciplina de graduação "Planejamento Arquitetônico I", ministrada para os alunos do $2^{\circ}$ ano, um ensino mais voltado ao Desenho Urbano, sem perder de vista a compreensão dos elementos que estruturam o espaço da cidade; entre os vários colegas com quem se trabalhou estavam os professores Adilson Macedo, Ari Fernandes, Clara Ant, Eulália Portela, Maria Lúcia Martins, Raquel Rolnik e Wilson Mariana. Pôde-se inserir noções importantes aprendidas com Magnoli sobre a paisagem urbana, sobre a importância dos espaços livres públicos na qualificação do desenho da cidade.

Após calorosos debates no Departamento de Planejamento da Faculdade de Arquitetura e Urbanismo da PUC-Campinas, realizou-se uma mudança de nomenclatura das várias disciplinas, visando adequá-las aos conteúdos que então já se praticavam. Dessa maneira, a disciplina acima mencionada mudou seu nome para "Urbanismo II". Já neste século, a disciplina contou sempre com a participação do Prof. Dr. Denio Benfatti. Estabeleceu-se a questão do projeto urbano como práxis central da disciplina e procura-se trabalhar desde questões da leitura do lugar, dos pressupostos do urbanismo moderno, sua crítica e as principais linhas do urbanismo contemporâneo que vem pautando projetos de requalificação e reabilitação urbana. A paisagem 
urbana, seus elementos referenciais, a qualificação dos espaços públicos e da mobilidade urbana são elementos norteadores dos exercícios projetuais. Tem-se claro que o projeto urbano pode-se constituir como prática interdisciplinar em que o paisagista tem muito a dizer, não apenas sobre qual arbusto colocar nessa ou naquela jardineira.

A interface entre Paisagismo e Urbanismo na PUC-Campinas não apenas se dá no âmbito da disciplina descrita acima. A idéia, cada vez mais disseminada, de que não se pode compreender o projeto do edifício isoladamente, mas sim discutindo arquitetura e cidade, produzindo interlocuções entre os projetos de arquitetura, de paisagismo e de urbanismo vem ganhando força na FAU-PUC-Campinas, resultando, entre outros, na inserção, no penúltimo semestre do curso de graduação, da disciplina de Projeto Urbano Integrado, pensada como síntese e fechamento do conjunto de disciplinas da graduação, antecedendo a atividade acadêmica do Trabalho Final de Graduação - TFG.

Na pós-graduação, as inter-relações entre Paisagismo e Urbanismo também se verificam na PUCCampinas. $\bigcirc$ curso de especialização Desenho e Gestão do Território Municipal - oferecido e realizado entre o final da década de 1990 e os primeiros anos da década atual - contou com uma disciplina denominada Paisagismo e Projetos Urbanos, tendo sido ministrada pelos professores Denio Benfatti, Eugenio Queiroga e Vladimir Bartalini. Novamente aqui se estabelecia claro diálogo entre os campos disciplinares do Paisagismo e do Urbanismo, entendia-se que esta era a melhor maneira de discutir a questão dos projetos urbanos contemporâneos e vários dos mais importantes projetos de espaços livres públicos urbanos contemporâneos colocavam-se também como Projetos Urbanos, haja vista, entre outras, as experiências parisiense e barceloneza realizadas a partir dos anos 1980.

No âmbito da pós-graduação stricto sensu, o Programa de Pós-Graduação em Urbanismo da PUC-Campinas possui uma disciplina intitulada Espaços Livres Públicos Urbanos. Originalmente, essa disciplina foi oferecida pelo professor Bartalini e, mais recentemente, está sob a responsabilidade do professor Queiroga. Trata-se de uma disciplina no campo do Paisagismo na qual se procura discutir, em momentos expressivos da produção paisagística ocidental, as questões culturais que se colocavam na área do Paisagismo, resultando nos diferentes valores de sociedade, de natureza e de desenho dos espaços livres. Estabelecem-se relações entre o desenho dos espaços livres públicos urbanos e a produção da cidade e das principais idéias urbanísticas de cada período analisado.

São ainda poucos, mas cada vez em maior número, os alunos do Programa de Pós-Graduação em Urbanismo da PUC-Campinas interessados em pesquisar os espaços livres públicos. Procurase, no presente, trabalhar com uma visão de espaço e paisagem ao mesmo tempo dialética e sistêmica, são claras as origens desta abordagem: Miranda Magnoli e Milton Santos.

\section{A Paisagem Como Futuro: Considerações Finais}

A paisagem é herança cultural, acumulação desigual dos tempos (SANTOS, 1996). A paisagem dialeticamente apresenta e encobre o tempo presente, o movimento da sociedade. É preciso "des-cobri-la", este é o esforço de Miranda Magnoli, e tal não se faz sem compreender a complexidade, dialética e sistêmica da paisagem, mesmo das que se apresentam, aparentemente, mais simples à visão.

A paisagem não apenas é herança, passado, pois como categoria interna do espaço ela é também presente, abriga em seu interior parte do sistema de ações que compõem o espaço - total. A paisagem não é apenas aparência da configuração espacial, é também existência que se transforma a cada movimento da sociedade e dos fenômenos biofísicos.

As ações são portadoras de intenções de futuro, realizam-se no presente, mas são resultado de diversos interesses de futuro. O Homem é projeto (SARTRE, 1973), embora apresente o pas- 
sado como herança, suas ações realizadas a cada tempo presente, visam ao porvir, imediato ou distante, pessoal ou coletivo. Se o homem é projeto, a paisagem, criação sempre presente do homem, também o é. Ao abrigar um subsistema de ações, a paisagem, como construção humana sobre o suporte biofísico, indica projetos de futuro, já realizados e realizando-se, de forma integral ou parcial.

A paisagem se apresenta como campo fértil para o futuro, sobre ela homens, empresas e instituições constroem, no cotidiano, seus planos territoriais, sejam de dominação, sejam de solidariedades orgânicas. Não são muitos os planos que consideram dialética e sistemicamente os aspectos sociais, estéticos e ambientais da paisagem. Compete ao arquiteto e urbanista uma difícil ação de convencimento junto do Estado, à sociedade civil e aos movimentos populares, da importância da paisagem em todas suas dimensões: social, estética e ambiental.

projeto da paisagem é manifestação cultural no espaço, seja ele elaborado por apenas um arquiteto ou por uma equipe multidisplinar integrada a um grupo social em um processo criativo participativo. Projetar a paisagem com liberdade e com a correspondente responsabilidade é tarefa humana, paisagística, que se apresenta a cada momento, com sua carga histórico-civilizacional. Projetar a paisagem envolve também a potência do novo, seja ele um projeto de restauro ou de maior transformação ambiental, é sempre o novo que se coloca enquanto projeto. Isso Magnoli nos ensina, questiona e provoca.

\section{Blibliografia}

GALENDER, Fany. Produção em pesquisa do grupo disciplinas Paisagem e Ambiente (GDPA) / FAUUSP (1973-2003). Paisagem e Ambiente: Ensaios, São Paulo: FAUUSP, n. 17, p. 123-21 1, 2003.

MAGNOLI, Miranda M. E. M. Espaços livres e urbanização: Uma introdução a aspectos da paisagem metropolitana. 1982. 116 p. Tese (Livre-docência em Estruturas Ambientais Urbanas) - Faculdade de Arquitetura e Urbanismo, Universidade de São Paulo, São Paulo, 1982.

O jardim na cidade é um fragmento de sonho. In: II ENCONTRO NACIONAL DE ENSINO DE PAISAGISMO $\overline{E M}$ ESCOLAS DE ARQUITETURA E URBANISMO DO BRASIL. 1996. São Paulo. Anais. São Paulo: Unimarco, 1996. p. 13-18.

QUEIROGA, Eugenio. A megalópole e a praça: O espaço entre a razão de dominação e a ação comunicativa. 2001. 351 p. Tese (Doutorado em Arquitetura e Urbanismo) - Faculdade de Arquitetura e Urbanismo, Universidade de São Paulo, São Paulo, 2001.

SANTOS, Milton. Espaço e método. São Paulo: Nobel, 1985.

Metamorfoses do espaço habitado. 4. ed. São Paulo: Hucitec, 1996.

A natureza do espaço: Técnica e tempo, razão e emoção. São Paulo: Hucitec, 1996.

Da paisagem ao espaço: Uma discussão. In: II ENCONTRO NACIONAL DE ENSINO DE PAISAGISMO EM ESCOLAS DE ARQUITETURA E URBANISMO DO BRASIL. 1996. São Paulo. Anais. São Paulo: Unimarco, 1996. p. 33-42.

Da totalidade ao lugar. São Paulo: Edusp, 2005

SARTRE, Jean-Paul. Questão de método. Tradução: Bento Prado Júnior. In: SARTRE, Jean-Paul; HEIDEGGER, Martin. O existencialismo é um humanismo. A imaginação. Questão de método. Conferências e escritos filosóficos. São Paulo: Abril, 1973. p. 115-197. (Coleção "Os pensadores - História das grandes idéias do mundo ocidental", v. XLV). 